\title{
Naturalized Philosophy of Science: A Cognitive Approach
}

\author{
Ulrich Frey \\ Technical University of Braunschweig
}

\begin{abstract}
Current debates in philosophy show an important distinction between naturalistic and non-naturalistic approaches. The explanatory power and shortcomings of both perspectives are discussed, and some consequences of a naturalistic perspective in the Philosophy of Science are explored. It is argued that every investigation into the scientific enterprise needs to consider the cognitive abilities of human beings, including scientists. Next to historical and sociological factors cognitive abilities are at the center of problem-solving or decision-making of individual scientists and therefore of paramount importance. Such an empirically based cognitive Philosophy of Science is demonstrated. This has often been called for, but has almost never been implemented. There are hardly any attempts to link empirical results from Cognitive Science to historical scientific case studies. This article argues for such an approach and puts it into practice with three short case studies. The main tenets of a naturalized Philosophy of Science are then derived from these considerations.
\end{abstract}

\section{A NATURALISTIC VIEW OF CURRENT PHILOSOPHY OF SCIENCE}

\subsection{Empirical Philosophy of Science}

This article tries to argue that only a naturalistic approach in the Philosophy of Science is feasible. Three case studies in the history of science are analyzed to strengthen this claim. We will call attention to how often it is necessary to revert to naturalistic means. Any approach to the Philosophy of Science without using methodological naturalism, that is results from natural sciences, is unable to explain as much as naturalistic approaches. 
This article is not about arguments for or against naturalism. Instead the analysis itself is one long demonstration to show that non-naturalistic approaches have to overcome too many problems, making naturalistic accounts the better analytic tool.

Naturalized Philosophy of Science has its focus on the cognitive abilities of scientists. That is to say research has to take into account how people_-scientists - think. More precisely: How do they solve problems and which cognitive mechanisms are used for solving the many day-to-day problems? Without considering evolutionary processes this cannot be answered: Like any other sophisticated trait of our body, the brain is an adaptation. Its structure as well as its inherent behavior has been shaped by our evolutionary history. For millions of years our brains had to solve problems of small hunter-and-gatherer groups. It seems evident that this left marks on the way humans think, on what we are able to do and what not. Cognitive abilities are important, not only the often cited historical or social background.

Details about strengths and weaknesses of the human mind can be uncovered by empirical investigations, most prominently Cognitive Psychology and Evolutionary Psychology. These disciplines give answers to the How? and Why? of human cognitive abilities. A complete analysis in Philosophy of Science may not do without integrating empirical results from Cognitive Sciences and Evolutionary Biology. This applies even for sociological studies interested for example in group interactions: There are some sociobiological fundamentals (here: about group behavior) which cannot be neglected when analyzing scientists at work. The following cognitive approach takes this into account claiming that there is an important connection between empirical results from evolutionary and cognitive psychology and scientific performance.

To prove that claim we will look more closely at a special case of cognitive abilities: Are there any systematic scientific errors directly connected to cognitive errors? If we recognize that the problems of our ancestors do not match with the problems of today, especially not with scientific problems, then it would appear reasonable to expect that many cognitive errors should arise from that discrepancy. These errors can in turn be explained by Cognitive Science and evolutionary accounts. 


\subsection{Neglect of cognitive aspects in the Philosophy of Science}

Philosophy of Science has been less concerned about cognitive factors so far, rather focusing on historical (Kuhn 1962/1976, Feyerabend 1976) and social aspects (Knorr Cetina 2002) or on rationality and progress (Popper 1934/1994, 1972/1998; Laudan 1977; Lakatos 1978/1982; Kitcher 1993; Callebaut 1993; Vollmer 1993). Exceptions are Tweney et al. (1981), Giere (1988, 1992) and Dunbar (2002), who analyze scientific discoveries from a cognitive-psychological perspective.

In contrast to that noticeable lack of publications in the "Cognitive Philosophy of Science", there are quite a few announcements (see Callebaut 1993; Ruse 1995; Kitcher 1993) demanding to take Cognitive Sciences seriously and incorporate them in case studies under the label Cognitive Philosophy of Science - closely linked to Psychology of Science. Unfortunately-and this is an important objection-almost no historical scientific case studies based on empirical results from Cognitive Science are available. There are hardly any attempts to link empirical results from say Biology or Psychology to historical examples.

However, it will not be sufficient to do Cognitive Philosophy of Science. Empirical research from Cognitive Psychology often enough only describes human abilities, but does not explain them. Possible explanations can be derived from Evolutionary Psychology (Cosmides \& Tooby 1992), Evolutionary Epistemology (Vollmer 1975/2002) and Evolutionary Biology. These disciplines rest on a solid empirical basis, which is exactly where philosophers of science should look for support. This article tries to show how such an approach could look like.

In contrast to cognitive aspects, sociological factors influencing scientific work have been studied extensively. In my opinion such kinds of explanation are, however, seriously flawed. I will confine my criticism to three points.

(1) Criticism: "Despite decades of research on this issue, cognitive sociologists have yet to produce a single general law which they are willing to evoke to explain the cognitive fortunes of any scientific theory, from any past period." (Laudan 1977, 217/218, emphasis in the original) 
(2) Criticism: If there are indeed negotiations in the laboratoryand not even the most ardent naturalist would deny thatwhat are the negotiations about? Prior in time and logic is the interaction with entities of the real world (and even social-constructivists are ontological realists, see Knorr Cetina in Callebaut 1993).

(3) Criticism: Social-constructivists should be able to show that identical social circumstances produce in fact the same kind of science (Kitcher 1993). This has not been shown yet.

\section{METHODOLOGICAL NATURALISM AND ITS CRITICS}

Before proceeding to the proposed naturalistic (evolutionary-cognitive) approach it is necessary to define naturalism more precisely.

\subsection{A definition of naturalism}

The term naturalism is rather vague and often used in many different notions by proponents and opponents alike. In its most trivial sense it means taking natural sciences seriously-a statement everybody would agree with. A more ambitious and precise definition qualifies naturalism in ontological respects as materialistic, in methodological respects as making the heaviest possible use of natural sciences and in epistemological respects as proposing a hypothetical realism (see Sukopp 2006).

This article will mostly be concerned with methodological aspects, that is how Philosophy of Science relates to natural sciences. It depends on natural sciences in at least three ways. Firstly, and rather trivially so, science and natural sciences in particular are its subject. Secondly, philosophers have to use data from natural sciences to support their hypotheses and claims - there is no such thing as a priori philosophy. Some might raise the objection that this is a circular argument as the studied subject itself is used to support theories about it; but this is common for many sciences: language is used to do linguistic studies, neurophysiologists use their brains to research them, theories about groups are discussed in groups, and so on. These examples are virtuous circles (see Vollmer 1975, 113f.). Thirdly, the hypotheses about science 
themselves have to be grounded in empirical research. If we suppose that a theory about the influence of scientific group structure on its research output is proposed, this claim would certainly have to recognize some very basic facts about groups known from sociobiology. If the claim contradicts well-established sociobiological facts, then in most cases the hypothesis should deservedly be rejected.

Furthermore, it cannot be denied that modern science contributes to genuine philosophical questions. Take Philosophy of Mind. Spectacular details from PET-scans and fMRI (functional Magnetic Resonance Imaging) allow new insights and are about to explain ancient riddles of Philosophy like freedom of will, body-mind problem etc. This, however, is not undisputed; the common reaction from philosophers is to cede to the empirical results while declaring that the problem itself is not touched by it. This I would call a forced withdrawal.

Some areas of research within the natural sciences, however, are essential for Philosophy of Science. Among them is Evolutionary Biology answering questions about our origin and our biological history as well as Cognitive Psychology answering questions about our mental abilities. Other sub-disciplines like Evolutionary Psychology or Sociobiology could be included making the relevant subjects by no means complete. The next section is dedicated to defending these essential disciplines against criticism.

\subsection{Rejection of criticism on Evolutionary Epistemology and} Evolutionary Psychology

The most common (but not the most valid) criticism against evolutionary accounts, such as Evolutionary Epistemology or Evolutionary Psychology, include the criticism of nativism, panadaptionism and the claim that evolutionary theories are not falsifiable. Neither of the first two are in fact claimed by any proponent (see for example Cosmides and Tooby 1994), while the third point cannot really be doubted: There are numerous empirical studies with over 10.000 humans which do make testable and falsifiable predictions (see Buss 1989).

Some other criticism-like the weak empirical basis of Evolutionary Psychology—looses rapidly justification: Recent neurophysiology results 
and empirical psychology support its predictions very well. The most fundamental critique claims that Evolutionary Epistemology is not a "complete" epistemology; real philosophical problems are not within its explanatory framework. However, the first is true for all epistemological approaches ( $t u$ quoque-argument). Moreover, philosophers are well advised to confine their theories, as too encompassing approaches have regularly turned out to be too ambitious. In fact, approaches including Evolutionary Epistemology which cover "only" part of the whole usually turn out to be both more useful and more correct than "big picture" theories.

Summing it up: It is safe to say that disciplines based on evolutionary theory both stood the test of time and defended themselves well against criticism - they are testable, empirically precise, and conceptually valid. It is on the contrary approaches which do not take evolutionary aspects into account that have to justify their applicability and claims.

\subsection{Rejection of criticism on Cognitive Philosophy of Science}

As this article voices claims about cognitive factors in science these hypotheses shall be defended against criticism, too.

(1) Criticism: Cognitive Philosophy of Science has no philosophical relevance, it does not solve any philosophical problem.

Reply: It is true that this approach is an example of a descriptive, concrete and empirical oriented Philosophy of Science. It is the opposite of the typical, often found very abstract, broad and general top-down-approach. Especially because such speculative approaches failed so often in the past when applied to specific historical examples, this provides an argument of how not to do it.

(2) Criticism: In order to investigate science (being a cultural activity) evolutionary shaped cognitive thinking patterns are not relevant at all. The connection is too far-fetched or even non-existent. 
Reply: That is the very connection this article tries to show. The "gap" can in fact be closed quite easily (see section 3). Cognitive peculiarities of humans - in this case, cognitive errors-occur both systematically and repeatedly in science. These errors are structurally identical with cognitive errors produced in controlled experiments in the laboratory. The easiest and most obvious explanation for these errors is that they originate in the same source, for example a certain error-prone thinking pattern. It will be shown that this relates the two levels seemingly so far apart.

(3) Criticism: There are other, better explanations. Theories and their errors are dependent on the background theories of each era and are adapted accordingly to the changing background.

Reply: Historical examples show that this hypothesis is not entirely tenable. It cannot explain why the same errors occur in medicine in the $16^{\text {th }}$, in physics in the $18^{\text {th }}$ as well as in psychology in the $20^{\text {th }}$ century, which can be shown. Practically every part of the so called "background" has been changed or has never been the same in the first place.

\section{A NATURALISTIC ACCOUNT OF SCIENTIFIC ERRORS}

So far the article has argued against possible criticism. Now, positive evidence for a Cognitive Philosophy of Science shall be presented. The focus is on cognitive errors of scientists, a research topic very suitable to show that Philosophy of Science has to rely on natural sciences when trying to explain phenomena from the history of science. The first example is the framing effect in medicine.

\subsection{The framing effect in medicine}

Physicians sometimes tend to have "peculiar" habits when deciding about therapies. If they heard or read about a therapy in a negative formulation, like "7 out of 100 patients die from this treatment" they are more likely to abandon this kind of therapy than when they encounter the same therapy in 
a positive formulation, like "93 out of 100 patients survive this treatment". This is called the framing effect (for an overview see McGettigan et al. 1999).

This decision making procedure is remarkable, as the same number of patients will die or survive in both formulations. The only difference is the frame-negative vs. positive. But surely this simple "trick" cannot influence trained experts, physicians with a doctoral degree and years of practical experience? Surprisingly, however, it can, and the effects are quite large: 25 to 42 per cent are influenced by the framing effect (McNeil et al. 1982). How are we to explain this fact? Why do scientists (here: physicians) behave so irrationally? While traditional philosophers of science are at a loss to explain, this is nevertheless a valid question. In contrast, for naturalized philosophers of science the answer is easy, as the framing effect is a rather well-known fact in Cognitive Psychology. Studies concerning the framing effect comprise well over 30.000 people of all ages, professions and education levels (see Kühberger 1998). It is simply one of the many cognitive errors human beings commit. It is trivial, yet has dramatic implications for the patients. Additionally, it is systematic. Detailed empirical studies show how and when this phenomenon occurs and supply the data including an explanation.

This kind of naturalistic analysis-coupling cognitive errors known from the natural sciences with (historical) scientific case studies-is obviously a powerful method. It is surprising how often errors in science have already been described in natural sciences, such as Cognitive Psychology and this can be backed up by further examples coming from widely different fields.

\subsection{Common errors with complex systems}

Many experiments have shown that the majority of subjects (laymen) have great difficulties with complex systems. However, almost every scientific problem is in some form complex, which means that errors should be common in problem-solving strategies of scientists, always assuming that scientists are not totally different from laymen at least in cognitive respects. A closer look reveals in fact that some errors occur again and 
again when subjects handle complex systems (after Dörner 1989). The most common are:

(1) Oversimplification (complex systems are reduced to simple, linear systems with one dominant cause. Side effects, long range effects, feedback-loops and other decisive characteristics of the system are simply ignored.).

(2) Overgeneralization (a general rule is deduced from one or few cases).

(3) Underestimation (a general tendency to underestimate the overall complexity).

(4) Isolated treatment (networks are treated as isolated systems).

(5) Underestimation of non-linear processes.

(6) Fixation on the situation (the momentary situation is regulated instead of the dynamic process).

(7) Too little control (no checks, too little gathering of information, no analysis of own measures).

(8) Blindness against own errors.

(9) Not learning from own errors.

(10) Wrong problem-solving priorities (problems are solved by conspicuousness instead of importance).

(11) Misplaced sphere of competence (methods of one's own competence are transferred to areas unsuitable for them, thus producing errors).

These are just some of the most common reactions and strategies of most humans when they have to deal with complex systems. We can classify these errors in three categories: Firstly, oversimplification on all levels (1-4). Secondly, significant problems with time (5-6). Thirdly, errors in strategychoice (6-11).

The most severe error is oversimplification, that is reduction of complex systems (1-4). In most cases a linear problem-solving strategy is used: Problem A has to be solved, therefore solution A'. This, however, creates problem $\mathrm{B}$; this is solved, but creates problem $\mathrm{C}$ and so on. This cascade of problems could have been avoided in the first place, if $\mathrm{B}$ and $\mathrm{C}$ had been anticipated while solving A; However, this is practically never the case. 
This short and necessarily incomplete account of problems with complex systems should make us wary whenever we watch scientists work with complex systems. It is not unlikely that they will commit the same errors as laymen. Three case studies (section 4) will demonstrate that this is indeed the case. But still an explanation is needed why human beings have so much trouble handling complex systems; so far, cognitive errors have only been described.

\subsection{Evolutionary explanation}

The way in which human beings handle complex situations is a reaction to a certain environment. It is a complex world we live in. It must be processed so that we can handle it. In a lot of situations it is imperative to act fast while at the same time we must not be impaired by incomplete or wrong information in our decisions.

All the said requirements are fulfilled by the above mentioned "errors". In a more positive formulation these mechanisms enable us to act at all: Complicated estimates are reduced to simple and linear extrapolations, networks of multiple causes and effects are simplified to one cause, alternatives are cut off, measures taken are not controlled and just a few examples are sufficient to deduce general laws.

From an evolutionary perspective these "errors" are very appropriate measures to come to terms with complex situations under time pressure, incomplete information and capacity limitations (for example memory). To achieve this, humans use heuristics that succeed in trading off minimal resources with sufficient precision. These adaptations aim at swiftness and simplicity. This is predominantly achieved by reduction as is evident from the mechanisms. A short look at our environment is enough to show why this has to be like that: It is impossible to process all the information. Only $1 \%$ of the already strongly filtered sensory input is computed, much less is actually used or remembered (von Ditfurth 1976). Furthermore there are nearly endless combinatorial possibilities of the existing data. This requires radical reduction and radical simplification on all levels. This has been spelled out in detail and tested empirically (see Dörner 1989; Gigerenzer \& Todd 1999). 


\section{HISTORICAL SCIENTIFIC CASE STUDIES}

It should have become clear by now that natural sciences like Cognitive Psychology and Evolutionary Biology can offer good descriptions and explanations of phenomena that are of interest in the Philosophy of Science. The fact that cognitive explanations are indeed at the very center of research is demonstrated in the following three historical scientific case studies where exactly the same cognitive errors are found as known from experiments in the laboratory.

\subsection{Case study 1: Introduction of new species—snails}

Ecosystems are complex systems. Humans have tampered with ecosystems as long as human history, due to which many species have become extinct (for example the Dodo or the Cassowary). However, introductions of species in existing ecosystems are every bit as disastrous. The following examples deal only with deliberate introductions by scientists or by politicians guided by scientific advice, to make sure that only scientific errors and not political considerations are investigated.

A very prominent example of linear problem-solving is the attempt to repair former mistakes: If an introduced organism does not fulfill its assigned role, the typical reaction is to introduce another organism. This second organism, so the argument, shall fight and destroy the first one.

One first example is the giant snail Achatina fulica, which was introduced in Asia as food source for the local population around 1910 to 1940, in Hawaii in 1955 (Cook 1989) and in Tahiti in 1967 (Murray et al. 1988). Growing exponentially, Achatina rapidly became the worst snail pest in the tropics (Mead 1961; Cowie 2001). For that reason two predatory snail species, Euglandina rosea and Gonaxis kibweziensis were introduced in Hawaii. The first did not only fail to prey on Achatina as expected (Griffiths et al. 1993, 79), but exterminated nearly every endemic snail species (Cowie 2000, 145)! Only 10 to $35 \%$ of the former 750 species are alive today (Cowie 2001). The same error was made when many Partula-snails in Tahiti went extinct by Euglandina (Cook 1989). In the mentioned cases the decision to introduce the predatory snails was reached by committees of scientific experts (see Mead 1961, 128ff). And 
even after Euglandina another twelve snails have been introduced with the same intent but without success (Cowie 2001).

Many more errors are apparent: The ecosystem as a network is not considered at all (instead: two snails, nothing else), feedback-loops and interdependencies are neglected (the fact that Euglandina feeds on other snails). Instead we notice a radical simplification towards one goal (extinction of Achatina), which shall be accomplished by one measure alone (Euglandina). If the first "solution" does not work, then the same strategy is repeated with even worse consequences (Euglandina and then twelve other snails).

Moreover, in many countries the introductions were never tested before their implementation. There was neither a control of the measures nor an analysis of errors (a typical error, see section 3.2). The one study in Hawaii that was done before Euglandina was introduced consisted of determining whether Euglandina preyed upon Achatina at all. It did, although once in the wild it unfortunately preferred nearly entirely smaller snails (Cook 1989). And worse: as soon as Euglandina was introduced into the wild, nobody cared about what happened at all.

However, the lack of follow-up, both in terms of determining its impact on crop pests and in ensuring that it does not cause damage to native species, is striking. (Griffiths et al. 1993, 80)

There was neither a detailed search for information nor reliable empirical data about how Euglandina and Achatina populations would interact when in the same habitat (Christensen 1984; Murray et al. 1988). On the contrary, there was convincing evidence that they would not interact (see Cowie 2001). Even the commissioned scientific expert for that purpose, Kondo, and the expert on Achatina, Mead, had to confess their ignorance-but recommended the introduction nevertheless, although Mead himself cites half a page of literature indicating the dangers of new introductions (Mead 1961). But as soon as 1957 it was known by experiments that Euglandina preferred smaller snails to Achatina-even if experts still predicted the opposite (Mead 1961, 132).

These examples show the transferability of many cognitive errors from experimental test situations in the laboratory to actual decisions by 
scientists-they are in fact committed by scientists, experts, and laymen alike.

\subsection{Case study 2: More harmful introductions of species}

Psychological research (Dörner 1989, see section 3.2) shows that it is very hard to learn from own mistakes and this is exactly what can be seen in many historical examples encompassing disciplines, countries, and epochs:

A major theme of this book [about harmful introductions] is that we do not learn from history, that we continue to emulate the mistakes of the past. (Low 1999, XXVI)

Interestingly enough, the success quota of biological introductions to fight other introduced species is well-known: Only $6 \%$ were completely successful, $18 \%$ were somewhat positive, but an overwhelming $76 \%$ were totally unsuccessful (Low 1999; see also Cowie 2001 for similar figures for snail introductions).

In spite of that there are plenty of current examples: As late as 1988, Australia introduced a grass (Hymenachne amplexicaulis) despite being very aware of negative effects of biological introductions. Only eleven years later this grass is counted as one of the top twenty worst weeds, because it displaces other endemic species. Two years later, in 1990, Kochia (Bassia scoparia) was introduced for land reclamation; only five years later half a million Dollar had to be invested to get the problem under control. The Australian government based both decisions on scientific expertise and was-due to former unsuccessful introductions-clearly aware of harmful effects accompanying introductions of new species; thus, these considerations played a central part in the decision-making process. Nevertheless the errors were committed again. For an overview of harmful introductions, see Kowarik (2003) and the Invasive Species Specialist Group (Invasive Species Specialist Group (ISSG) 2005).

Although most of the introductions of the past were quite problematic or even bordering on catastrophes, the future will be even worse: Genetically altered organisms have a still higher destructive potential. The consequences of such introductions are not in the least foreseeable, much less controllable. So even right now we do not learn from well-known 
mistakes in the past, but instead increase the potential for disaster at a scale not yet to be overseen: The genetically altered seaweed Caulerpa taxifolia is seven times bigger as its unaltered counterpart and has escaped to the Mediterranean Sea beginning to cover increasingly larger parts of the sea floor (Low 1999).

At the same time this last case is an example for another error-to have too little information to act in an appropriate manner but act nevertheless. The same goes for the introduction of the Aga-toad (Bufo marinus) in Australia to fight a pest feeding on sugar cane-the only information about the suitability of the toad to fight the pest was the correlation of the population sizes of these two species in one country (Puerto Rico) in one year (1931). There was indeed a decline of the pest in this year-however, this was due to high rainfalls, not to the toad. Today the toad is one of the most devastating pests in Australia (Low 1999).

Adding to this underestimation of complexity and the resulting insufficient gathering of information are three more errors: Future trends are mostly extrapolated in a linear way, long-range effects are neglected and cause and effects with large time-lags between the two are extremely difficult to master:

Another difficulty is that cause and effect, in invasion biology, are often far removed from each other, separated by time, and often by space. (Low 1999, 293)

Many more cognitive errors of scientists could be demonstrated (see Frey 2007), but the similarity of errors known from the laboratory and historical case studies should be apparent by now.

\subsection{Case study 3: Long-term management of ecosystems}

The best examples to illustrate the general inability of humans to manage complex systems are those where the opposite of the desired and planned effects occurred. Take the management of the Blue Mountain forests in Oregon, USA. Over a 100-year period (1900-2006) we see case after case of mismanagement: 
In the process of trying to manage extremely complex landscapes, foresters set into motion a chain of events that increasingly swung out of control. (Langston 1995, 8)

The most important goal of the National Forest Service-since 1900-has been to regulate the forest in order to create sustainable, "efficient", and productive forests consisting mostly of valuable pines. A look at the forest today shows us that not a single one of these most important goals has been achieved. Instead, the opposite developments emerged.

The first example are firs. After 100 years of efforts to increase the pine population firs have become the most prevalent tree in the forest and have replaced the desired pines for the most part. This in turn has had unwanted and unforeseen side-effects. One of them is the massive loss through pests against which firs are less resistant than pines. Although this fact has been known since 1913 (see Bright 1913) it came as a surprise to foresters.

Why did firs replace pines? It was known that pines needed more light than firs. Therefore, cutting more clearings was thought to be a sufficient measure. This oversimplification on one aspect of the problem is typical for linear problem-solving. Foresters missed another crucial factor-firs grow faster than pines, thus the clearings were colonized by firs (Langston 1995; the preferred cutting of pines is another contributing reason). As the pines did not grow as anticipated by this measure this approach was abandoned altogether-there was no more sowing of pine seeds at all. Instead a new single solution was proposed: proper fire fighting. Unfortunately this, too, did not work out as planned.

A second example is the fire fighting itself. To foresters "efficient" management meant to fight small and middle-sized fires. This, however, lead to high losses through uncontrollable major fires. These major fires occurred only because fuels could accumulate in great amounts because small fires were extinguished:

The very effort to avoid forest fires has helped, in a later generation, to create them. (Little 1995, 84)

Moreover, these misguided attempts of fire fighting made the pest problem much worse:

[...] a kind of worst-case scenario come true. (Little 1995, 84) 
Nevertheless the National Forest Service does not appear to have learnt from its own mistakes: The new fire fighting program costs are two billion US-Dollar just for the year 2000 (USDA Forest Service 2005a), although it is known from the management of the Yellowstone National Park that the most efficient and least expensive fire fighting is: doing nothing at all. Almost all fires burn out relatively quickly by themselves (Clark \& Minta 1994).

We notice at least three unwanted results of the forest regulation: firs instead of pines, devastating fires and pest problems. Let's take a closer look at the measures that produced the pest problems:

The massive pest problem began around 1969. Two main causes can be identified: Firs were much more susceptible to pests than pines and dead wood was lacking, because it had been cleared away to increase productivity. Dead wood, however, is an integral part of forests, providing nutrients, shadow and humidity for young trees. Furthermore it is the preferred habitat of predatory insects and insect-eating ants (Campotonus). These ants in turn are the main food source $(98 \%)$ of woodpeckers. Woodpeckers, however, were neglected in considerations, because they do not prey on pests. But they create nesting opportunities for other birds preying on insects. As neither ants nor birds controlled them, the number of insects exploded. Very fast this turned into a catastrophe: In $199050 \%$ of the Douglas-firs had been destroyed by insects and $63 \%$ of all trees had been damaged (Langston 1995; Little 1995).

If human beings were good at learning from their mistakes, this could be corrected in the future. Unfortunately, this is not the case, as can be seen in the current forest plan (valid until 2006): Again the National Forest Service expects maximum growth, coming about through a disappearance of all limiting factors (for example no insects) coupled with an increase of all positive factors. The enormous conflicts between grazing, protection of biodiversity, forest growth and the recreational value of the forest are mentioned, but "solved" by referring to scientific progress. This progress will make it possible to attain two goals at the same time, even if they are mutually exclusive (USDA Forest Service 1990, 3f. to 4-17). These errors are by now familiar to us, as they occur again and again and are wellknown from controlled laboratory experiments. 
These three examples $(5.1,5.2,5.3)$ have shown how a cognitive analysis of historical case studies could look like. The next two chapters convert this analysis into arguments for naturalistic approaches in general.

\section{ARGUMENTS FOR AN EVOLUTIONARY-COGNITIVE PHILOSOPHY OF SCIENCE}

The probably most convincing arguments for an evolutionary-cognitive approach, that is the systematic integration of experimental evidence from natural sciences into Philosophy of Science are as follows:

(1) Argument of cognition: It can't be doubted that science is primarily a cognitive activity. The basic level of science is about daily problem-solving, mental model building, finding new analogies, and so on. Generally speaking, how scientists think should be of high importance to philosophers of science (and, of course, to scientists themselves).

(2) Argument of relevance: The relevance of psychological experiments concerning thinking is high and hardly disputable. On the one hand there are studies in the Philosophy of Science connecting these two convincingly (for example Wimsatt 1980). On the other hand independent historical studies which have nothing to do with Psychology describe strategies and errors of scientists as if they were describing the cognitive errors known from experimental psychology-without knowing that the latter exist. Complementary, there are psychological studies which establish a direct link from psychological errors to errors in science (see section 3.1; McNeil et al. 1982; Wimsatt 1980).

(3) Argument of Similarity: The similarity of experimentally proven errors with existing errors in the history of science is remarkable. It is often possible to see them as identical. There is no reason to pass over the most simple and most evident explanation: These errors are based on the same faulty cognitive mechanisms. 
(4) Argument of invariance: Many historical examples show clearly the invariance of errors. This is important, because it excludes rival explanations: A look at the "cold fusion" episode in 1989 shows that many errors-excluding fraud issues-occurred. But paradigmatic interpretations have a hard time explaining them, as there was no paradigm of "cold fusion". A similar problem arises for historical interpretations for very similar, if not identical phenomena occurring in very different epochs. One salient example are the attempts to measure skulls and intelligence differences between races (Gould 1988). It is easy to find very similar errors from 1840 to 2006, while the historical preconditions and background theories vary considerably during that time.

(5) Argument of being the only explanation: For the case study of handling complex systems (here: the management of ecosystems) the evolutionary-cognitive explanation is the only valid one. For how else can one hope to understand the apparent and systematic inability of humans to handle complex systems? It seems evident that humans are simply not made for this and therefore reach their cognitive limits.

(6) Argument of universality: The best argument for evolutionary-cognitive explanations is evidence from different cultures and (if possible) from children. This evidence can in fact be provided (see Samuels \& McDonald 2002; Cosmides \& Tooby 1997). Furthermore, many historical examples span centuries as well as disciplines as different as anthropology, physics, medicine or psychology (see Frey 2007). Further evidence comes from Gigerenzer and Hoffrage (1995): The more ecologically valid (that is similar to natural environments for humans) tasks are formulated, the better the subjects perform.

These arguments are at the heart of a Cognitive Philosophy of Science. But cognitive factors are certainly not the only influencing element. There are many interactions between cognitive, social and historical influences which weaken and amplify each other. 
After these six arguments in favor of my hypothesis, two possible falsifications shall be mentioned: My hypothesis would be falsified, if an independent historical examination of the used case studies cannot find the described errors or if many new case studies were completely without evolutionary-cognitive aspects.

\section{ARGUMENTS FOR A NATURALIZED PHILOSOPHY OF SCIENCE}

The data mentioned above shall now be integrated into a naturalized Philosophy of Science. Often enough, proposals on how to do Philosophy of Science have a weakness: They do not describe the real history of science accurately enough and too often have not even tried to. If-and this is true even for the most famous philosophers such as Kuhn or Lakatos-their theoretical postulates are tested empirically with diverse historical case studies, most postulates turn out to be outright false (see Donovan, Laudan \& Laudan 1988/1992).

One of the most promising attempts to solve these intricate problems is that of a naturalized Philosophy of Science, as advocated by Giere (1988; 1992). This approach in its minimal form has two demands: The first methodological rule is that empirical evidence is of foremost importance. Each and every theory has to be verified by case studies. Secondly, results from natural sciences have to be at the core of Philosophy of Science: This applies to generating hypotheses as well as to testing them. Both demands have not been met in Philosophy of Science, although this has been slowly changing in the last years.

In this article I have tried to show the importance of these two points. As can be seen by the three short case studies it is indispensable to rely on results from natural sciences, and the two disciplines with probably the most prominent influence on scientific activities are Cognitive Psychology and Evolutionary Biology.

Take one example from the very heart of Philosophy of Science: the principle of falsification. This is, since Popper, one of the most important tools for evaluating theories. But are human beings able to falsify correctly and do they in practice try to falsify their own theories? The sobering answer is: no. Wason (1968) and many follow-up studies (for example Griggs \& Cox 1982) show that only about $2-5 \%$ of the tested persons 
solve an easy task by using falsification. So, although the theoretical necessity to falsify remains unchallenged, falsification in practice is far from being used consistently.

The necessity of an integrated, naturalized analysis is also evident from the historical development of Philosophy of Science in the $20^{\text {th }}$ century. All modern conceptions differentiated science more and more, painting a picture where scientists are under the spell of many influences, determining their work. All these descriptions, however, are too narrow: they confine themselves to social and historical influences, while other influences have almost completely been forgotten: Human beings are not only sociocultural beings, but also biological organisms. This is the point where a naturalized Philosophy of Science has its focus and complements traditional approaches. Psychological and biological aspects of our mental structure have to be considered.

Philosophy of Science (and Epistemology) is researching an empirical phenomenon, that is the cognitive products and methods of biological human subjects with certain abilities as well as limits. This puts cognitive products at the center of attention. If one sees science primarily as a problem-solving activity - and many philosophers of science do that (for example Popper 1972/1998; Lakatos 1978/1982; Laudan 1977)—then the focus of research has to be the process of thinking, more precisely the process of problem-solving. Thus, the level of our inquiry refers to the daily scientific work which consists of a huge number of small decisions, evaluations, solutions to practical problems and so on. But many philosophers of science choose a coarser unit of inquiry, for example research programs or research traditions. Many phenomena are missed that way, because strengths and weaknesses of our thinking processes have to be considered for answering them.

It is difficult to say why this important approach has been overlooked for so long. One possible reason is that it seems impossible to generalize individual cognitive processes. However, naturalists are only interested in the cognitive processes that are common to all individuals. There are loads of data concerning human problem-solving, decision-theory, confirmation of hypotheses which are all relevant to discoveries (for example Tooby \& Cosmides 1992; Gigerenzer 1999). 


\section{CONCLUDING REMARKS}

I have tried to emphasize how essential it is for Philosophy of Science to rely on natural sciences as methodological means. However, there are points where naturalists can agree with non-naturalists. I agree with Kuhn, Feyerabend, Latour and Knorr Cetina in their criticism of the "received view" of science as being too simplistic. Social and historical factors are important. It is, however, indispensable to add another important influencing factor: the cognitive side of science (psychological and biological explanations). An account focusing on cognitive aspects can complement these theories. This has been an area of neglect to date, but humans are first and foremost biological beings.

To sum up: What can one expect of a naturalistic approach to the Philosophy of Science?

(1) The focus is on the cognitive (psychological and biological) attributes of human beings (scientists).

(2) These attributes are not subject to speculation, as they are supported by many empirical results from Cognitive Science.

(3) These results in turn can be explained by Evolutionary Biology and Evolutionary Psychology.

(4) Historical and social factors are not neglected-they are complemented.

(5) Theories in the Philosophy of Science need always be warranted by historical case studies as another source of empirical support.

With these points in mind modern Philosophy of Science should be able to progress in describing science more and more precisely-a naturalized Philosophy of Science is progressive. 


\section{REFERENCES}

Bright, G. A. 1913: Umatilla National Forest Annual Silvical Report. The relative merits of western larch and Douglas-fir in the Blue Mountains, Oregon.

http://www.fs.fed.us/r6/uma/history/index.htm (20.02.06).

Buss, D. M. 1989: Sex differences in human mate preferences: Evolutionary hypotheses tested in 37 cultures. Behavioral and Brain Sciences 12, 1-49.

Callebaut, W. 1993: "Conversations with William Bechtel, Robert N. Brandon, Richard M. Burian, Donald T. Campbell, (...)." In Callebaut, W. (ed.) Taking the Naturalistic Turn or How Real Philosophy of Science is Done. Chicago: University of Chicago Press. Christensen, C. C. 1984: Are Euglandina and Gonaxis Effective Agents for Biological Control of the Giant African Snail in Hawaii? American Malacological Bulletin 2, 98-99.

Clark, T. W. and Minta, S. C. 1994: Greater Yellowstone's Future: Prospects for Ecosystem Science, Management, and Policy. Moose, Wyoming: Homestead Publishing.

Cook, A. 1989: "Factors Affecting Prey choice and Feeding Technique in the Carnivorous Snail EUGLANDINA ROSEA FERUSSAC." Journal of Molluscan Studies 55, 469-477.

Cosmides, L. and Tooby, J. 1994: Beyond intuition and instinct blindness: toward an evolutionarily rigorous cognitive science. Cognition 50, 41-77.

Cosmides, L./Tooby, J. 1997: Evolutionary Psychology: A Primer. http://cogweb.ucla.edu/ep/EP-primer.html (14.07.05).

Cowie, R. H. 2000: "Non-indigenous land and freshwater molluscs in the islands of the Pacific: Conservation impacts and threats." In: Sherley, G. (ed.) Invasive species in the Pacific: A technical review and regional strategy. Apia, Samoa: South Pacific Regional Environment Program, 143-172.

Cowie, R. H. 2001: "Can snails ever be effective and safe biocontrol agents?" International Journal of Pest Management 47, 23-40. 
Donovan, A., Laudan, L. and Laudan, R. 1988: "Testing Theories of Scientific Change.” In: Donovan, A., Laudan, L. and Laudan, R. (eds.) Scrutinizing Science: Empirical Studies of Scientific Change. Baltimore: John Hopkins University Press, 3-44.

Dörner, D. 1989: Die Logik des Mißlingens: Strategisches Denken in komplexen Situationen. Reinbek bei Hamburg: Rowohlt.

Dunbar, K. N. 2002: "Understanding the role of cognition in science: the Science as Category framework." In: Carruthers, P., Stich, S. and Siegal, M. (eds.) The cognitive basis of science. Cambridge: Cambridge University Press, 154-170.

Federspiel, K. and Herbst, V. 1991/1996: Stiftung Warentest: Die andere Medizin: Nutzen und Risiken sanfter Heilmethoden. Braunschweig: Westermann.

Feyerabend, P. K. 1976: Wider den Methodenzwang: Skizze einer anarchistischen Erkenntnistheorie. Frankfurt am Main: Suhrkamp.

Frey, U. 2007: Der blinde Fleck - Kognitive Fehler in der Naturwissenschaft und ihre evolutionsbiologischen Grundlagen. Frankfurt: Ontos.

Giere, R. N. 1988: Explaining Science: A Cognitive Approach. Chicago: University of Chicago Press.

Giere, R. N. 1992: "Introduction: Cognitive Models of Science.” In Giere, R. N. and Feigl, H. (eds.) Cognitive Models of Science. Minnesota Studies in the Philosophy of Science Volume XV. Minneapolis: University of Minnesota Press, xv-xxviii.

Gigerenzer, G. and Todd, P. M. 1999: Fast and Frugal Heuristics: The Adaptive Toolbox. In Gigerenzer, G., Todd, P. M. and ABC Research Group (eds.) Simple heuristics that make us smart. New York: Oxford University Press, 3-34.

Gigerenzer, G. and Hoffrage, U. 1995: "How to Improve Bayesian Reasoning without Instruction: Frequency Formats." Psychological Review 102, 684-704.

Gould, S. J. 1988: Der falsch vermessene Mensch. Frankfurt am Main: Suhrkamp.

Griffiths, O., Cook, A. and Wells, S. M. 1993: "The diet of the introduced carnivorous snail Euglandina rosea in Mauritius and its implications 
for threatened island gastropod faunas." Journal of the Zoological Society of London 229, 79-89.

Griggs, R. A. and Cox, J. R. 1982: "The elusive thematic-materials effect in Wason's selection Task." British Journal of Psychology 73, 407420.

Invasive Species Specialist Group (ISSG) (2005): 100 of the World's Worst Invasive Alien Species.

http://www.issg.org/database/species/search.asp?st=100ss\&fr=1\&sts= sss (31.01.06).

Kitcher, P. 1993: The Advancement of Science: Science without Legend, Objectivity without Illusions. New York: Oxford University Press.

Knorr Cetina, K. 2002: Wissenskulturen: Ein Vergleich naturwissenschaftlicher Wissensformen. Frankfurt am Main: Suhrkamp.

Kowarik, I. 2003: Biologische Invasionen: Neophyten und Neozoen in Mitteleuropa. Stuttgart: Ulmer.

Kühberger, A. 1998: "The Influence of Framing on Risky Decisions: A Meta-analysis." Organizational Behaviour and Human Decision Processes 75, 23-55.

Kuhn, T. S. 1962/1976: Die Struktur wissenschaftlicher Revolutionen. Frankfurt am Main: Suhrkamp.

Lakatos, I. 1978/1982: Die Methodologie der wissenschaftlichen Forschungsprogramme: Philosophische Schriften Band 1. Edited by Worrall, J. and Currie, G. Braunschweig: Vieweg.

Langston, N. 1995: Forest Dreams, Forest Nightmares: The Paradox of Old Growth in the Inland West. Seattle: University of Washington Press.

Laudan, L. 1977: Progress and its Problems. Berkeley: University of California Press.

Little, C. E. 1995: The Dying of the Trees: The Pandemic in America's Forests. New York: Viking Penguin.

Low, T. 1999: Feral Future: The Untold Story of Australia's Exotic Invaders. Chicago: University of Chicago Press.

McGettigan, P., Sly, K., O'Connell, D., Hill, S. and Henry, D. 1999: "The Effects of Information Framing on the Practices of Physicians." Journal of General Internal Medicine 14, 633-642. 
McNeil, B. J., Pauker, S. G., Sox, H. C. and Tversky, A. 1982: "On the elicitation of preferences for alternative therapies." New England Journal of Medicine 306, 1259-1262.

Mead, A. R. 1961: The Giant African Snail: A Problem in Economic Malacology. Chicago: University of Chicago Press.

Murray, J., Murray, E., Johnson, M. S. and Clarke, B. 1988: "The Extinction of Partula on Moorea." Pacific Science 42, 150-153.

Popper, K. 1972/1998: Objektive Erkenntnis: Ein evolutionärer Entwurf. Hamburg: Hoffmann und Campe.

Popper, K. R. 1934/1994: Logik der Forschung. Tübingen: Mohr Siebeck.

Ruse, M. 1995: Evolutionary Naturalism: Selected Essays. London: Routledge.

Samuels, M. C. and McDonald, J. 2002: "Elementary School-Age Children's Capacity to Choose Positive Diagnostic and Negative Diagnostic Tests." Child Development 73, 857-866.

Sukopp, T. 2006: Naturalismus - Kritik und Verteidigung erkenntnistheoretischer Positionen. Frankfurt am Main: Ontos.

Tweney, R. D., Doherty, M. E. and Mynatt, C. R. 1981: "General Introduction.” In: Tweney, R. D., Doherty, M. E. and Mynatt, C. R.: On Scientific Thinking. New York: Columbia University Press.

USDA Forest Service 1990: Umatilla Forest Land and Resource Management Plan.

http://www.fs.fed.us/r6/uma/projects/index.shtml (15.02.06).

USDA Forest Service 2005: Research \& Development 2004 Annual Report.

http://www.fs.fed.us/research/pdf/2004-annual-report.pdf (10.03.06).

Vollmer, G. 1975/2002: Evolutionäre Erkenntnistheorie: Angeborene Erkenntnisstrukturen im Kontext von Biologie, Psychologie, Linguistik, Philosophie und Wissenschaftstheorie. Stuttgart: Hirzel.

Vollmer, G. 1985/2003: Was können wir wissen? Band 1. Stuttgart: Hirzel.

Vollmer, G. 1986/2003: Was können wir wissen? Band 2. Stuttgart: Hirzel.

Vollmer, G. 1993: Wissenschaftstheorie im Einsatz: Beiträge zu einer selbstkritischen Wissenschaftstheorie. Stuttgart: Hirzel.

Von Ditfurth, H. 1976: Der Geist fiel nicht vom Himmel: Die Evolution unseres Bewußtseins. Hamburg: Hoffmann und Campe. 
Wason, P. 1968: "Reasoning about a Rule." Quarterly Journal of Experimental Psychology 20, 273-281.

Wimsatt, W. C. 1980: "Reductionist research strategies and their biases in the units of selection controversy." In Nickles, T. (ed.): Scientific Discovery: Case Studies. Dordrecht: Reidel, 213-259. 